\title{
IDEOLOGI GENDER KEBAHASAAN PADA NOVEL KARYA SASTRA PENGARANG PEREMPUAN
}

\section{GENDER IDEOLOGY OF HUMANITY IN THE WOMEN'S NOVEL}

\author{
Heny Roulina Sitepu' ${ }^{1}$, T. Silvana Sinar ${ }^{2}$, Irawaty Kahar ${ }^{3}$ \\ Universitas Sumatera Utara \\ HP. 082165393119 \\ henyrou@gmail.com
}

Naskah diterima tanggal 24 Oktober 2018

Naskah direvisi terakhir tanggal 6 September 2019

\begin{abstract}
The novel by female authors often tell about the position of women who appear as symbols of subtlety, and place them in a lower position than men. The purpose of this study is to analyze how the form of linguistic gender ideology in literary novels by female authors and what context triggers gender ideology in novels by literary authors. In this study, researchers focused on this research on the Mills Kritsis Discourse Analysis. This research is a type of qualitative research. The data in this study is sentences that contain linguistic by female authors. Data collection techniques in this study use document recording techniques. Based on the results of data analysis it is known that the form of linguistic gender ideology in literary novels of female authors is dominated by the form of subordination that is 20 data or about (60.53\%), while 18 (14.37\%) other data leads to stereotypes for readers of literary novels, especially literary works of female authors, to foster interest in preserving literary novels, especially literary novels, especially authors
\end{abstract}

Keywords: Novel by Female Author, Ideology, Linguistic Gender, Critical Discourse Analysis

\begin{abstract}
Abstrak
Novel karya sastra pengarang perempuan sering berkisah mengenai posisi perempuan yang muncul sebagai simbol kehalusan, dan menempatkannya pada kedudukan yang lebih rendah dibandingkan laki-laki. Adapun tujuan penelitian ini yaitu untuk menganalisis bagaimana bentuk ideologi gender kebahasaan pada novel-novel karya sastra pengarang perempuan. Pada penelitian ini, peneliti menitikberatkan penelitian ini pada Analisis Wacana Kritis model Mills dengan jenis penelitian kualitatif. Data pada penelitian ini adalah kalimat yang mengandung ideologi gender kebahasaan pada novel karya pengarang perempuan. Teknik pengumpulan data dalam penelitian ialah mencatat dokumen. Berdasarkan hasil analisis data diketahui bahwa bentuk ideologi gender kebahasaan pada novel-novel karya sastra pengarang perempuan didominasi oleh bentuk subordinasi yaitu terdapat 20 data atau sekitar $(60,53 \%)$, sedangkan $18(14,37 \%)$ data lainnya mengarah kepada stereotipe. Bagi pembaca novel-novel karya sastra terkhusus karya sastra pengarang perempuan agar menumbuhkan minat untuk ikut melestarikan novel sastra khususnya novel karya sastra khususnya pengarang
\end{abstract}

Kata Kunci : Novel Pengarang Perempuan, Ideologi, Gender Kebahasaan, Analisis Wacana Kritis

\section{PENDAHULUAN}

Karya sastra merupakan duplikat dari realita kehidupan. Sastra sebagai bagian dari kebudayaan memiliki peranan yang cukup besar dalam mendokumentasikan apa yang terjadi di dalam masyarakat. Segala bentuk peristiwa yang terjadi, menjadikan sastra sebagai bentuk keluhan, kritik, cacian, dan sindiran. Namun pada dasarnya, sastra merupakan bentuk bahasa yang tidak lain memiliki sifat menghibur (Teeuw, 1984:183).

Masalah-masalah yang diangkat oleh pengarang dalam karya sastra biasanya tidak 
terlepas dari pengalaman nyata dalam kehidupan sehari-hari. Hanya saja dalam penyampaiannya, pengarang harus menambah dan mengemas terlebih dahulu gaya bahasa yang menarik, sehingga dapat membuat pembaca terbawa masuk ke dalam karya sastra tersebut (Saryono, 2009: 16-17).

Salah satu bentuk karya sastra adalah novel. Novel merupakan hasil karya sastra yang di dalamnya mengungkapkan masalahmasalah yang terdapat dalam kehidupan, baik yang berkaitan dengan nilai-nilai sosial, filsafat, moral, religius, maupun hal-hal yang ada di dalam kehidupan (Sugihastuti dan Suharto, 2002: 43).

Sebagai salah satu karya sastra, novel memiliki ciri khas tersendiri bila dibandingkan dengan karya sastra lain. Novel dianggap mampu untuk menampung jalannya kisah kehidupan, sehingga novel dapat menjelaskan secara detail keseluruhan apa yang terjadi pada kisah tersebut. Kisah yang dimuat dalam novel pun beragam. Ada kisah percintaan, penindasan, sosial, agama, sindiran, ekonomi, dan ketidaksetaraan gender. Kisah pada novel tersebut dikemas cukup panjang dengan bahasa yang menarik (Nurgiyantoro, 2009:10).

Apabila melihat isi novel, khususnya novel-novel karya sastra pengarang perempuan Indonesia sering berkisah mengenai posisi perempuan yang muncul sebagai simbol kehalusan dan menempatkannya pada kedudukan yang lebih rendah dibandingkan laki-laki. Keistimewaan dari novel-novel karya sastra pengarang perempuan ialah, mereka dapat menyampaikan makna dan pesan cerita melalui kacamata perempuan. Dengan mencoba mengangkat dan memperjuangkan kaum perempuan pada posisi yang sebenarnya yakni sejajar dengan laki-laki dengan cara mempersoalkan pemahaman kaum laki-laki yang cenderung mendudukkan perempuan dalam inferioritas (Saryono, 2009: 19).

Pada penelitian ini, peneliti menganalisis dua novel karya sastra pengarang perempuan yaitu novel Cerita Cinta Enrico karya Ayu Utami (2012) dan
Jangan Main-Main dengan Kelaminmu karya Djenar Maesa Ayu (2008).

Novel-novel karya pengarang perempuan tersebut pun tidak ada yang bebas dari keberpihakan. Keberpihakan tersebut murni dari opini pengarang itu sendiri pada kelompok sosial tertentu. Keberpihakan tersebut mendorong novel dicap sebagai karya sastra yang tendensius artinya adalah novel tersebut memiliki tujuan-tujuan tertentu dibalik pembuatannya. Hal ini tidaklah mengherankan mengingat novel tercipta dari aspirasi pengarang terhadap problem sosial yang terdapat dalam masyarakat itu sendiri (Ratna, 2005:370).

Saptari dan Holzner (1997: 221-222) menyatakan bahwa keberpihakan yang tercipta dari aspirasi pengarang terhadap problema sosial terbukti mempunyai pengaruh besar dalam membentuk ideologi gender. Oleh karena itu representasi gender dalam novel termasuk relatif menonjol dan kuat.

Gender merupakan perbedaan status dan peran antara perempuan dan laki-laki yang dibentuk oleh masyarakat sesuai dengan nilai budaya yang berlaku dalam periode waktu tertentu. Dengan berkembangnya subordinasi dan stereotipe yang tidak adil terhadap perempuan, maka sering terjadi ketidakadilan terhadap perempuan (Fakih, 2006: 12-13).

Salah satu yang sangat fenomenal dalam masalah gender yang ada di dalam sebuah novel adalah gender kebahasaan. Gender kebahasaan merupakan pengungkapan gaya dan kemungkinan soal ketabuan bahasa yang digunakan oleh pengarang novel, baik pengarang laki-laki maupun perempuan. Bahasa laki-laki dan perempuan pada sebuah novel memiliki perbedaan, perempuan kerap jadi subordinasi kaum laki-laki dalam bahasa yang diwujudkan pada berbagai unsur kosa kata, ungkapan, istilah, dan tataran gramatikalnya (Kridalaksana, 2008:229).

Misalnya penggunaan bahasa pada novel Cerita Cinta Enrico karya Ayu Utami pada penggalan teks berikut: 
"Pergaulan di sana sangat bebas. Ibuku tidak tahu bahwa aku sudah pernah berbuat itu dengan perempuan di kota sunyi ini. Ada satu cewek cantik yang sangat bagak. Aku ciuman dengannya di tepi laut di atas motorku saat malam Minggu, dan ia tidak memakai beha. Aku telah siap dengan kondom yang kubeli di apotek sebelumnya. Umurku lima belas." (Cerita Cinta Enrico, hlm. 83)

Pada kalimat bercetak tebal di atas, terdapat beberapa kalimat berupa pengungkapan gaya dan kemungkinan soal ketabuan bahasa yang diucapkan oleh tokoh utama pada novel yang berjenis kelamin laki-laki yang mengarah kepada subordinasi perempuan yaitu "Aku ciuman dengannya di tepi laut", "ia tidak memakai beha", "Aku telah siap dengan kondom". Kalimat bercetak tebal di atas merupakan bentuk gender kebahasaan, yang mana tokoh Enrico sebagai tokoh utama pada novel ini terkesan melakukan pelanggaran privasi seorang perempuan dan mengganggap bahwa perempuan lebih rendah dibandingkan lakilaki melalui penggunaan bahasa yang tabu. Sehingga pada penggalan novel di atas Enrico telah melakukan subordinasi terhadap lawan jenisnya.

Selain itu, subordinasi perempuan juga terdapat pada novel Jangan Main-Main dengan Kelaminmu karya Djenar Maesa Ayu (2008), seperti yang terlihat pada kutipan berikut.

"Saya heran, bisa juga seonggok daging itu hamil. Padahal saya hanya menyentuhnya sekali dalam tiga bulan. Itu pun karena kasihan. Juga dengan ritual, minum ginseng supaya ereksi. Karena saya terbiasa sudah melihat dan menikmati keindahan. Tubuh tinggi semampai. Kaki belang. Rambut panjang. Leher jenjang. Pinggang bak gitar. Dan dua buah dada besar. Ah... seperti apakah bentuknya nanti setelah melahirkan? ( Jangan Main-

Main dengan Kelaminmu, hlm. 18)

Pendeskripsian terhadap bagianbagian tubuh oleh pengarang melalui tokoh suami, merupakan bentuk "realitas" yang mungkin ada dalam benak suami di alam realitas sebagai wujud pemberontakan. Pada penggalan novel ini, pengarang menunjukkan bahwa perempuan kerap disubordinasi dalam rumah tangga, yaitu pada penggalan kalimat yang mengarah kepada hasrat seksual yang dialami suami mulai kendur dan bosan terhadap istrinya. Sehingga untuk melakukan kewajibannya sebagai suami pun harus membayangkan sesosok perempuan dengan kriteria Kaki belang, rambut panjang, leher jenjang, pinggang bak gitar, dan dua buah dada besar.

Tokoh suami pada penggalan novel ini telah biasa melakukan hubungan kelamin dengan perempuan-perempuan lain (teman tokoh suami/selingkuhan) sebagai bentuk penyimpangan sosial dilakukan oleh tokoh laki, penghianatan bersilang yang semuanya berlaku di kota atau metropolitan, ketika kejujuran, integritas, kesabaran, tanggung jawab menjadi barang mahal. Tubuh dan seks sebagai modal untuk mempertahankan demi keberlangsungan hidup.

Berdasarkan penggalan-penggalan novel di atas, menunjukkan bahwa kedua pengarang novel tersebut mempresentasikan ideologi gender kebahasaan pada novelnya. Melalui hal-hal tersebut, pengarang novel mengarahkan atau memberikan pandangan keberadaan sekitarnya melalui ideologi yang digunakan, dan ideologi tersebut memang berkaitan merujuk kepada agama dan religi, keyakinan, nilai-nilai, dan konsep ideal.

Hadirnya ideologi pada sebuah novel bertujuan untuk menawarkan perubahan, memperbaiki tatanan yang sudah ada, atau bahkan mengubah total kebiasaan (Roekminto, 2008: 2). Misalnya pada penggalan novel karya Ayu Utami

"aku akan merona ketika ibu memuji pekerjaanku. Hatiku berdebar-debar manakah ia mengenakan pantovel itu 
dikakinya. Kakinya yang kokoh dengan betis penuh. Tidak seperti kakiku dan ayah seperti ceker ayam. Slup sepasang pantovel itu terpasang cantik dan gagah, menyangga seluruh bagian tubuhnya. Dia menjelma sesosok dewi. Rok lebar menutupi kaki ibuku dan mengecil di pinggang. Ia mengenakan atasan putih dengan sedikit renda di dada dan lengan. Rambutnya segarr tidak seperti rambut perempuan lain yang cepal oleh minyak dan menyimpan banyak kutu. Ibuku adalah perempuan tercantik, teranggun, dan termaju di seluruh duniaku" (Cerita Cinta Enrico, hlm. 31-32).

Pada penggalan novel di atas, pengarang novel menawarkan sebuah ideologi perubahan, dengan mencoba mengangkat dan memperjuangkan kaum perempuan pada posisi yang sebenarnya yakni sejajar dengan laki-laki yaitu pada kalimat "Kakinya yang kokoh dengan betis penuh. Tidak seperti kakiku dan ayah seperti ceker ayam" dan Rambutnya segar tidak seperti rambut perempuan lain yang cepal oleh minyak dan menyimpan banyak kutu"

Menurut Mills (1994) ideologi memiliki dua pengertian yang bertolak belakang, yakni secara positif dan secara negatif. Secara positif, ideologi dipersepsi sebagai suatu pandangan yang menyatakan nilai kelompok sosial tertentu untuk membela dan memajukan kepentingankepentingannya. Sedangkan secara negatif, ideologi dilihat sebagai suatu kesadaran palsu, yaitu suatu kebutuhan untuk melakukan penipuan dengan cara memutarbalikkan pemahaman orang mengenai realitas sosial (hlm. 13).

Analisis ideologi gender kebahasaan pada novel-novel pengarang sastra perempuan bertujuan untuk melihat jenis dan bentuk konstruksi ideologi gender yang terepresentasi dalam sebuah novel. Untuk mengetahui ideologi gender kebahasaan pada novel-novel karya sastra pengarang perempuan, maka diperlukan pisau analisis yang tepat untuk menganalisis novel-novel tersebut.

Sebagaimana diketahui bahwa, untuk mengetahui bagaimana ideologi pada sebuah novel, diperlukan penganalisisan wacana secara kritis. Analisis Wacana Kritis didefenisikan sebagai upaya untuk menjelaskan suatu teks pada fenomena sosial untuk mengetahui kepentingan yang termuat didalamnya. Novel sebagai bentuk praktik sosial dapat dianalisis dengan Analisis Wacana Kritis (Eriyanto, 2006: 7). Penganalisis wacana secara kritis didasarkan atas asumsi bahwa novel dapat dipandang sebagai wacana yang dapat mempelajari bagaimana dominasi suatu ideologi serta ketidakadilan dijalankan dan dioperasikan melalui teks atau wacana pada sebuah novel . Pada penelitian ini, peneliti menitikberatkan penelitian ini pada Analisis Wacana Kritsis model Mills (1994) yang memandang bahasa sebagai praktik sosial untuk memantapkan dan menyebarkan ideologinya. Model Mills (1994) lebih melihat bagaimana posisi subjek yang menjadi penceritaan dan siapa yang menjadi objek penceritaan, posisi tersebut penting untuk dikemukakan karena akan menentukan bagaiamana struktur teks dan bagaimana makna diperlakukan dalam teks secara keseluruhan (hlm. 87)

Selain posisi subjek-objek di atas, Mills (1994) juga menjelaskan posisi lain yaitup Pembaca dan penulis, bagaimana seorang pembaca akan memosisikan dirinya ketika membaca penceritaan teks, hal ini akan mempengaruhi bagaimana subjek-objek diinterpretasikan oleh pembaca. Penulis, bagaimana seorang pembaca akan memposisikan dirinya ketika membaca penceritaan teks, hal ini akan mempenaruhi bagaimana subjek-objek diinterpretasikan oleh pembaca (hlm. 89).

Secara keseluruhan proses analisis posisi ini akan membuat satu pihak menjadi legitimite dan pihak lain menjadi ilegitimite. Analisis Wacana Kritis model Mills (1994) berbeda dengan Analisis Wacana Kritis tokoh lain. Tokoh-tokoh Analisis Wacana 
Kritis tersebut lebih cenderung memusatkan perhatian pada pertarungan politik, kekuasaan dan gender. Seperti Foucault (1971) yang menganggap bahwa wacana merupakan alat bagi kepentingan kekuasaan, hegemoni, dominasi budaya dan ilmu pengetahuan. Leeuwen (2001) menganalisis bagaimana suatu kelompok atau seseorang dimarginalisasikan posisinya dalam suatu wacana. Sedangkan Mills (1994) memusatkan perhatian pada bagaimana pembaca memengaruhi bagaimana seharusnya teks itu dipahami dan bagaimana aktor sosial ditempatkan. Penceritaan dan posisi yang menjadikan satu pihak legitimate dan pihak lain illegitimate.

Peneliti melihat bahwa Analisis Wanaca Kritis Model Mills sangat tepat digunakan untuk menganalisis ideologi gender kebahasaan yang terdapat pada novelnovel karya sastra pengarang perempuan yaitu novel Cerita Cinta Enrico karya Ayu Utami (2012) dan Jangan Main-Main dengan Kelaminmu karya Djenar Maesa Ayu (2008), karena untuk mengetahui suatu bentuk ideologi, diperlukan perhatian yang penuh pada bagaimana pembaca memahami teks dan aktor yang terlibat di dalamnya.

Berdasarkan paparan di atas, peneliti tertarik untuk menganalisis novel-novel karya sastra pengarang perempuan yaitu novel Cerita Cinta Enrico karya Ayu Utami (2012) dan Jangan Main-Main dengan Kelaminmu karya Djenar Maesa Ayu (2008) dengan Analisis Wacana Kritis model Mills (1994).

\section{PEMBAHASAN}

Berdasarkan hasil analisis data tentang novel-novel karya pengarang objek (perempuan), diketahui bahwa novel tersebut lahir berdasarkan pengamatan sosial dari pengarang itu sendiri. Maraknya kasus perselingkuhan yang menjadikan perempuan (objek) sebagai pihak yang tersakiti dan memperoleh label negatif menjadi suatu inspirasi bagi pengarang itu sendiri untuk menulis cerita ketidaksetaraan gender melalui novelnya. Pada novel-novel tersebut diketahui adanya beberapa bentuk ketidaksetaraan gender antara lain.

\section{Subordinasi}

Subordinasi artinya suatu penilaian atau anggapan bahwa suatu peran yang dilakukan oleh satu jenis kelamin lebih rendah dari yang lain. Telah diketahui, nilainilai yang berlaku di masyarakat, telah memisahkan dan memilah-milah peran-peran gender, laki-laki (subjek) dan objek (perempuan). Pada novel ini, pengarang perempuan (objek) mengganggap bahwa perempuan (objek) dianggap bertanggung jawab dan memiliki peran dalam urusan domestik atau reproduksi, sementara lakilaki (subjek) dalam urusan publik atau produksi (Abdullah, 2006: 245).

Tapi, begitulah, perempuan (objek) diam-diam suka menjebak kita. Mereka buat diri mereka hamil dan mereka suruh kita bertanggung jawab. (Cerita Cinta Enrico, Ayu Utami)

Pada penggalan novel di atas, pengarang momposisikan dirinya sebagai laki-laki (subjek) yang menilai perempuan (objek) pada umumnya yang memandang perempuan (objek) seolah-olah lebih rendah dari subjek (laki-laki). Pengarang novel melihat bahwa laki-laki (subjek) pada umumnya memandang perempuan (objek) sebelah mata, dan tidak pernah mau mengakui perbuatan yang dia lakukan, meskipun perbuatan itu dilakukan bersama atas dasar suka sama suka. Laki-laki (subjek) pada kutipan novel tersebut cenderung egois dan menyalahkan perempuan (objek) sebagai pihak yang angkuh yang suka mengajak hal-hal yang tidak beretika. Sehingga pada kutipan ini, perempuan (objek) tersubordinasi.

Aku biasa membuat foto nude.
Inilah cara membuat
perempuan (objek) menjadi
obyek hasrat. (Cerita Cinta
Enrico, Ayu Utami)


Pengarang novel sengaja membahas tentang nude pada novelnya, sebagai seorang seniman, tentu saja bahwa pengarang perempuan (objek) tahu bahwa foto nude tersebut dijadikan sebagai konsumsi laki-laki (subjek) yang mensubordinasi perempuan (objek) melalui gambar. Pengarang memaparkan secara tersirat bahwa foto telanjang adalah foto yang sangat pribadi yang hanya boleh dilihat oleh diri sendiri dan pasangan resmi.

Tujuan pengarang sebagai objek (perempuan), setelah mengetahui betapa besar risiko yang ditimbulkan, maka sebaiknya seseorang bisa melindungi diri baik-baik dengan tidak memotret diri sendiri dalam kondisi minim busana. Mulai sekarang, harus ekstra waspada terhadap konten yang kita bagikan kepada orang lain, termasuk pasangan.

Selanjutnya pada penggalan novel berikut juga ada kalimat yang mensubordinasi objek (perempuan)

Saya heran, selama lima
tahun kami
hubungalin
hubun, tidak sekali pun
terlintas di kepala saya
tentang pernikahan. Tapi jika
dikatakan hubungan kami ini
hanya main-main, apalagi
hanya sebatas hasrat seksual,
dengan tegas saya akan
menolak. Saya sangat tahu
aturan main. (Cerita Cinta
Enrico, Ayu Utami)

Kalimat di atas adalah bentuk subordinasi laki-laki (subjek) pada perempuan (objek) dimana laki-laki (subjek) mengganggap bahwa perempuan (objek) adalah maklum rendah yang harus diberikan tindakan tegas agar tidak banyak tuntutan. Pengarang menyelipkan ideologi gender, karena pengarang melihat bahwa begitu banyak kejadian yang menimpa perempuan (objek) dalam hal seksual dan menjadikan perempuan (objek) hanya sebagai konsumsi seksual pria tanpa mau mempertanggung jawabkan perbuatannya.
Bagi pria semapan saya, hanya dibutuhkan beberapa jam untuk main-main, mulai main mata hingga main kelamin. Bayangkan! Berapa banyak main-main yang bisa saya lakukan dalam lima tahun. (Jangan Main-Main Dengan Kelaminmu, enar Maesa Ayu)

Kalimat di atas adalah bentuk subordinasi laki-laki (subjek) pada objek (perempuan). Pengarang novel mengamati dan menyimpulkan melalui penggalan berikut bahwa penggalan di atas merupakan perwakilan dari sifat laki-laki (subjek) yang merendahkan objek (perempuan), yang artinya perempuan (objek) dapat dengan mudah didapatkan

Kehamilan ini tidak juga membuat hati saya bahagia. Kehamilan ini membuat saya bingung. Apakah memang saya ditakdirkan untuk selamanya terperangkap dengan onggokan daging yang tak segar, gelayut lemak, dan bunyi kaleng rombeng, hanya karena saya terlanjur dikaruniai anak? Sahabat saya bilang, seharusnya saya bersyukur. Sebentar lagi saya akan diberi karunia dan diberi jalan untuk menata kembali rumah tangga saya. Apakah saya tidak berhak menentukan dan memilih kebahagiaan saya sendiri? (Jangan Main-Main Dengan Kelaminmu, enar Maesa Ayu)

Kalimat di atas adalah bentuk subordinasi laki-laki (subjek) pada perempuan (objek) dimana laki-laki (subjek) mengganggap bahwa perempuan (objek) adalah maklum rendah yang harus diberikan tindakan tegas agar tidak banyak tuntutan. Pengarang menyelipkan ideologi gender, karena pengarang melihat bahwa begitu banyak kejadian yang menimpa perempuan (objek) dalam hal seksual dan menjadikan 
perempuan (objek) hanya sebagai konsumsi seksual pria tanpa mau mempertanggung jawabkan perbuatannya.

Ketika pada suatu hari saya terbangun dan terperanjat di sisi seonggok daging tak segar dipenuhi gajih yang tak akan mudah hilang dengan latihan senam maupun fitness setiap hari sekalipun. (Jangan MainMain Dengan Kelaminmu, enar Maesa Ayu)

Penggalan novel di atas adalah bentuk ideologi pengarang untuk mendeskripsikan laki-laki (subjek) yang sudah bosan dengan istrinya dan membuat banyak alasan untuk berdalih, hal di atas merupakan bentuk subordinasi objek (perempuan), terlihat ketidaksetiaan laki-laki (subjek) kepada istrinya dan bahkan melakukan perselingkuhan tanpa sepengetahuan istrinya. perempuan (objek) pada penggalan novel ini sangat tidak mempunyai nilai dimata lakilaki (subjek) tersebut. Ini merupakan fenomena yang sering dijumpai pada masyarakat yang rumah tangganya hancur yang konon katanya disebabkan oleh kehadiran orang ketiga. Dan sudah pasti kehadiran orang ketiga adalah mengkambinghitamkan objek (perempuan). laki-laki (subjek) tidak pernah salah menurut mereka, mereka selalu menggagap bahwa mereka adalah korban dari rayuan maut objek (perempuan).

Dan ia melakukannya harus dengan kondisi lampu mati dan mata terpejam supaya memudahkannya

membayangkan untuk tinggi semampai, kaki belalang, rambut panjang, leher jenjang, pinggang bak gitar dan buah dada besar. Ah... saya tidak bisa bayangkan, apa yang akan terjadi setelah. (Jangan MainMain Dengan Kelaminmu, enar Maesa Ayu)
Kalimat di atas adalah bentuk subordinasi laki-laki (subjek) pada objek (perempuan). Pengarang novel mengamati dan menyimpulkan melalui penggalan berikut bahwa penggalan di atas merupakan perwakilan dari sifat laki-laki (subjek) yang merendahkan objek (perempuan), yang artinya perempuan (objek) dapat dengan mudah didapatkan Tidak adanya penghargaan sedikitpun yang diberikan lakilaki (subjek) kepada istrinya. Pengarang sengaja menyelipkan ideologi ini sebagai gambaran bahwa lelaki yang berselingkuh pada umumnya membayangkan selingkuhannya ketika sedang melakukan hubungan seksual dengan perempuan (objek) selingkuhannya. Hal tersebut tentu saja tidak adil bagi objek (perempuan).

Saya heran. Kehamilan ini tidak juga membuat hati saya bahagia. Kehamilan ini membuat saya bingung. Apakah memang saya ditakdirkan untuk selamanya terperangkap dengan onggokan daging yang tak segar, gelayut lemak, dan bunyi kaleng rombeng, hanya karena saya terlanjur dikaruniai anak? Sahabat saya bilang, seharusnya saya bersyukur. Sebentar lagi saya akan diberi karunia dan diberi jalan untuk menata kembali rumah tangga saya. Apakah saya tidak berhak menentukan dan memilih kebahagiaan saya sendiri? (Jangan Main-Main Dengan Kelaminmu, enar Maesa Ayu)

\begin{tabular}{|c|}
\hline $\begin{array}{lccr}\begin{array}{l}\text { Kalimat } \\
\text { subordinasi }\end{array} & \begin{array}{c}\text { laki-laki } \\
\text { latas }\end{array} & \begin{array}{c}\text { adalah } \\
\text { (subjek) }\end{array} & \begin{array}{r}\text { bentuk } \\
\text { pada }\end{array} \\
\text { perempuan } & \text { (objek) } & \text { laki-laki } & \text { (subjek) } \\
\text { mengganggap } & \text { bahwa } & \text { perempuan } & \text { (objek) } \\
\text { adalah maklum rendah yang harus diberikan }\end{array}$ \\
\hline
\end{tabular}


(objek) dalam hal seksual dan menjadikan perempuan (objek) hanya sebagai konsumsi seksual pria tanpa mau mempertanggungjawabkan perbuatannya.

Pandangan pengarang terhadap fenomena perselingkuhan yaitu adanya kebosanan dalam berumah tangga membuat banyak laki-laki (subjek) tidak menginginkan istrinya mengandung dan melahirkan anak. Hal tersebut merupakan suatu pemberontakan yang menandakan bahwa perempuan (objek) itu tidak layak untuk subjek (laki-laki). Hal ini menyudutkan objek (perempuan). Oleh sebab itu melalui novelnya, pengarang berusaha membuka wawasan seseorang yang sedang mengalami keretakan rumah tangga agar waspada dengan gerak-gerik, tingkah laku suami atau istri.

\section{Stereotipe}

Stereotipe adalah pelabelan atau penandaan terhadap suatu kelompok tertentu. Salah satu jenis stereotipe bersumber dari pandangan gender. Banyak sekali ketidakadilan terhadap jenis kelamin yang bersumber dari penandaan (streotipe) yang dilekatkan pada mereka. Laki-laki dipersiapkan untuk menjadi tiang keluarga, sedangkan perempuan hanya sebagai pengurus rumah tangga, kalaupun mereka bekerja, hasilnya dianggap tambahan, oleh sebab itu, pendidikan perempuan dinomorduakan (Abdullah, 2006: 246).

Aku menginginkan perempuan (objek) sebatas teman tidur. (Cerita Cinta Enrico, Ayu Utami)

Pada penggalan teks di atas, pengarang novel menghadirkan sebuah ideologi yang mengarah kepada strereotipe objek (perempuan), yaitu pada kalimat "perempuan (objek) sebatas teman tidur" Berdasarkan paparan di atas, dapat dilihat bahwa pengarang perempuan (objek) memposisikan perempuan (objek) seperti pelampiasan subjek (laki-laki), yang kapan saja ingin dipakai perempuan (objek) dapat memenuhinya. Sementara bahasa yang digunakan oleh pengarang perempuan (objek) tersebut sangat tabu digunakan pada saat berbincang-bincang dengan orang. Apabila kata-kata tersebut diposisikan kepada laki-laki (subjek)" laki-laki (subjek) hanya sebatas teman tidur". maka semua akan terasa biasa-biasa saj, tidak ada hal yang tabu di dalamnya. Sehingga pada penggalan novel ini, pengarang mensubordinasikan objek (perempuan).

Data selanjutnya tentang stereotipe laki-laki (subjek) kepada perempuan (objek) yaitu:

\section{Tapi, aku selalu}

memperlakukan pacar-pacarku dengan manis. Cuma, mereka selalu punya harapan lebih. (Cerita Cinta Enrico, Ayu Utami)

Pada penggalan teks di atas, pengarang novel menghadirkan sebuah ideologi yang mengarah kepada strereotipe objek (perempuan). Adanya pemikiran bahwa perempuan (objek) adalah makhluk yang bisa dibohongi dan dengan mudahnya dapat menjadi korban seorang subjek (lakilaki). Berdasarkan paparan di atas, dapat dilihat bahwa pengarang perempuan (objek) memosisikan perempuan (objek) seperti pelampiasan subjek (laki-laki), yang kapan saja ingin dipakai perempuan (objek) dapat memenuhinya dengan dalih akan menagih janji dari pria tersebut.

Pengarang dalam hal ini mengungkapkan alasan beberapa laki-laki (subjek) ketika sedang mendekati seorang objek (perempuan). Laki-laki (subjek) akan mengeluarkan sejuta jurus rayuan gombal untuk dapat memperoleh apa yang mereka inginkan dari objek (perempuan), namun setelah mereka mendapatkannya maka apapun janji yang mereka berikan sebelumnya tidak akan pernah betul-betul menjadi kenyataan.

"Seks itu selalu problematis, Sayang," bisiknya. "Lebih baik kita mengakuinya." Ia mencium dan berkata nakal, "Sejujurnya, menurutku seks itu tidak pernah sakral. Hanya pastor zaman 
ini yang bilang begitu. Sebab, mereka tidak punya kemewahan untuk berkata jujur dan mereka harus menjaga perasaan umat. (Cerita Cinta Enrico, Ayu Utami)

Pada penggalan teks di atas, pengarang novel berusaha membenarkan tindakan laki-laki (subjek) dan perempuan (objek) dalam kegiatan seksual. laki-laki (subjek) berusaha meyakinkan perempuan (objek) bahwa berhubungan seksual itu merupakan kebutuhan dan dosa tidak ada di dalamnya. pengarang berusaha meyakinkan pembaca bahwa apapun akan dikatakan seorang laik-laki ketika telah menyukai seorang perempuan (objek) apalagi meminta perempuan (objek) tersebut untuk melakukan hubungan seksual dengannya serta menghubungkan aktifitas seksualnya dengan kehidupan keagamaan yang cenderung menyalahkan pemimpin agama, dan seolaholah bahwa tokoh-tokoh agama tidak pernah setuju tentang seks adalah dosa.

"Lihat," katanya seusai bercinta. "Setiap kali kita bercinta sungguhan dengan pasangan baru, rasanya begitu indah seolah-olah kita tidak pernah merasakannya sebelumnya. (Cerita Cinta Enrico, Ayu Utami)

Pada penggalan teks di atas, pengarang novel pada penggalan novel ini, berusaha menyadarkan pembaca bahwa kegiatan seksual yang dilakukan adalah dengan bermacam-macam orang hasilnya akan sama saja, tidak baik apabila dilakukan dengan banyak orang, Pengarang novel mengajak pembaca agar tidak tergerus oleh nafsu dan tetap menjaga hubungan seksualnya hanya dengan pasangannya saja. perempuan (objek) tidak harus menutup mata melihat dan mendengar rayuan gombal dari pria yang bukan pasangannya.

Bagi pria semapan saya,
hanya dibutuhkan beberapa
jam untuk main-main, mulai
main mata hingga main
kelamin. Bayangkan! Berapa
banyak main-main yang bisa
saya lakukan dalam lima
tahun. (Jangan Main-Main
Dengan Kelaminmu, enar
Maesa Ayu)

Berdasarkan data di atas, pengarang novel memposisikan perempuan (objek) sebagai makhluk yang rendah, yaitu dengan adanya perbedaan sosial misalnya seperti pada data di atas "Bagi pria semapan saya, hanya dibutuhkan beberapa jam untuk main-main, mulai main mata hingga main kelamin. Bayangkan! Berapa banyak mainmain yang bisa saya lakukan dalam lima tahun.

Pada penggalan novel tersebut di atas, dapat diketahui bahwa ada alasan pengarang menulis perbedaan ini, apakah penulis berkiblat pada perempuan (objek) atau justru lebih cenderung membela kaum subjek (laki-laki). Pada kalimat tersebut jelas terlihat bahwa perempuan (objek) lebih rendah dari pada subjek (laki-laki).

Tabel Bentuk Ideologi Gender Kebahasaan pada novel Karya Sastra Pengarang perempuan, yaitu pada novel Cerita Cinta Enrico dan novel Jangan Main-Main dengan Kelaminmu

\begin{tabular}{|l|l|c|c|}
\hline \multirow{2}{*}{ No } & \multirow{2}{*}{ Jenis Data } & \multicolumn{2}{|l|}{ Bentuk Ideologi Gender Kebahasaan } \\
\cline { 3 - 4 } & & Subordinasi & Stereotipe \\
\hline 1 & Kalimat & $\checkmark$ & - \\
\hline 2 & Kalimat & - & $\checkmark$ \\
\hline 3 & Kalimat & $\checkmark$ & - \\
\hline 4 & Kalimat & - & $\checkmark$ \\
\hline 5 & Kalimat & - & $\checkmark$ \\
\hline
\end{tabular}




\begin{tabular}{|c|c|c|c|}
\hline 6 & Kalimat & - & $\checkmark$ \\
\hline 7 & Kalimat & - & $\checkmark$ \\
\hline 8 & Kalimat & $\checkmark$ & - \\
\hline 9 & Kalimat & $\checkmark$ & - \\
\hline 10 & Kalimat & - & $\checkmark$ \\
\hline 11 & Kalimat & - & $\checkmark$ \\
\hline 12 & Kalimat & - & $\checkmark$ \\
\hline 13 & Kalimat & $\checkmark$ & - \\
\hline 14 & Kalimat & $\checkmark$ & - \\
\hline 15 & Kalimat & $\checkmark$ & - \\
\hline 16 & Kalimat & - & $\checkmark$ \\
\hline 17 & Kalimat & - & $\checkmark$ \\
\hline 18 & Kalimat & $\checkmark$ & - \\
\hline 19 & Kalimat & $\checkmark$ & - \\
\hline 20 & Kalimat & - & $\checkmark$ \\
\hline 21 & Kalimat & - & $\checkmark$ \\
\hline 22 & Kalimat & $\checkmark$ & - \\
\hline 23 & Kalimat & $\checkmark$ & - \\
\hline 24 & Kalimat & - & $\checkmark$ \\
\hline 25 & Kalimat & - & $\checkmark$ \\
\hline 36 & Kalimat & - & $\checkmark$ \\
\hline 27 & Kalimat & - & $\checkmark$ \\
\hline 28 & Kalimat & - & $\checkmark$ \\
\hline 29 & Kalimat & $\checkmark$ & - \\
\hline 30 & Kalimat & $\checkmark$ & - \\
\hline 31 & Kalimat & $\checkmark$ & - \\
\hline 32 & Kalimat & $\checkmark$ & - \\
\hline 33 & Kalimat & - & $\checkmark$ \\
\hline 34 & Kalimat & $\checkmark$ & - \\
\hline 35 & Kalimat & $\checkmark$ & - \\
\hline 36 & Kalimat & $\checkmark$ & - \\
\hline 37 & Kalimat & $\checkmark$ & - \\
\hline 38 & Kalimat & $\checkmark$ & - \\
\hline \multicolumn{2}{|c|}{ Jumlah } & $20(60,53 \%)$ & $18(47,37 \%)$ \\
\hline
\end{tabular}

\section{PENUTUP}

lainnya mengarah kepada stereotipe.

\section{Simpulan}

Berdasarkan analisis yang dilakukan Saran

terhadap novel-novel karya pengarang perempuan yaitu novel Cerita Cinta Enrico karya Ayu Utami dan novel Jangan mainmain dengan kelaminmu karya Djenar dapat disimpulkan bentuk ideologi gender kebahasaan pada novel-novel karya sastra pengarang perempuan didominasi oleh bentuk subordinasi yaitu terdapat 20 data atau sekitar $(60,53 \%)$, sedangkan $18(14,37 \%)$ data
1. Pengarang novel perempuan sebaiknya harus tetap menggunakan kata-kata atau kalimat yang sopan sesuai dengan citra bangsa Indonesia yang berbudaya. Karena perempuan merupakan makhluk yang lemah lembut dan identik dengan tutur kata yang santun.

2. Pembaca diharap berpikiran kritis dalam menganalisa setiap kata, kalimat 
dan paragraf pada novel-novel karya sastra pengarang perempuan agak tidak timbul kesalahpahaman dalam memaknai isi novel tersebut.

3. Diharapkan agar dapat memperluas dan memperkaya penelitian mengenai ideologi gender kebahasaan dalam novel karya sastra khususnya pengarang perempuan, agar dapat memberikan masukan-masukan yang berharga terhadap keperluan kritik sastra dalam pengembangan telaah linguistik sebuah novel.

4. Bagi pembaca novel-novel karya sastra

\section{DAFTAR PUSTAKA}

Abdullah, Irwan. (2006). Sangkan Paran Gender. Yogyakarta: Pustaka Pelajar Althusser, Louis. (1969). Tentang Ideologi: Strukturalisme Marxis, Psikoanalisis. Cultural Studies. Yogyakarta: Jalasutra

Aulya, Siti Dara Nirmala. (2014). "Woman Linguistic Features Reflected by Margaret Thatcher in the Film Iron Lady". Study Program of English, Department of Language and Literature, Faculty of Cultural Studies, Universitas Brawijaya Ayu, Djenar Maesa. (2008). Jangan MainMain dengan Kelaminmu. Jakarta; KPG (Kepustakaan Populer Gramedia)

Coates. (1993). Gender. Retrieved September $3<\mathrm{www}$. course1.winona.msus.edu/ pjohnson /gender /spender4.htm

Cook. (2001). Physics of the earth and planet. Halsted Press Book, New York.

Dijk, Teun A. Van. (1993). Handbook of Discourse Analisis: Discourse Analisys in society. London. Academic Press, Inc.

Djajnegara, Soenarjati. (2000). Kritik Sastra Feminis: Sebuah Pengantar. Jakarta:

Gramedia Pustaka Utama. terkhusus karya sastra pengarang perempuan agar menumbuhkan minat untuk ikut melestarikan novel sastra khususnya novel karya sastra khususnya pengarang

\section{Ucapan Terima Kasih}

Terima kasih penulis sampaikan kepada bapak ibu dosen universitas Sumatra utara sehingga tulisan ini dapat selesai, dan terima kasih kepada semua pihak yang sudah membantu penulis.

Eriyanto. (2006). Analisis Wacana: Pengantar Analisis Teks dan Media. Yogyakarta: LkiS

Faircough, Norman. (1995). Critical Discourse Analysis. New York: Longman Group Limited.

Fakih, Mansour. (2006). Analisis Gender \& Transformasi Sosial. Yogyakarta: Pustaka Pelajar.

Foucault, M .1971. L'ordre du discours. Gallimard. Paris

Halliday, M.A.K. (2004). Language as Social Semiotics. London: University Park Press.

Handayani. (2001). Konsep dan Teknik Penelitian Gender. Malang: UMM press.

http://www.koalisiperempuan.or.id/2011/0 5/04/ideologi-gender/

Kress. (1979). Language is ideology. Routledge \& Kegan Paul

Kridlaksana, Harimurti. (2008). Kamus Linguistik. Edisi Keempat. Jakarta: PT Gramedia Pustaka Utama.

Kristeva, Nur Syaid Santoso. (2004). Negara Proletar dan Revolusi Proletar, Yogyakarta: Pustaka Pelajar

Lakoff. (1975). Language and Woman's Place. New York: Harper \& Row.

Lakoff. (2004). Metaphors We Live by Second Edition. Chicago: University of Chicago Press 
Leeuwen T. Van. (2001). Multimodal discourse: the modes and media of contemporary communication. London. Arnold

M. Asaf Amir, Asim Mehmood. (2018). Critical Discourse Analysis of Tariq Ali's Novel "The Stone Woman": A Corpus Driven Study". International journal.

Meutia. (2018). "Tinung" Dalam Film Ca

Bau Kan: Analisis Wacana Kritis dalam Perspektif Gender

Miles, Metthew B, A. Michael Huberman and Johnny Saldana. (2014). Qualitative Data Analysis, A Methods Sourcebook, Third Edition. Sage Publications, Inc.

Mills, Sara. (1994). Critical Discourse Analysis of Female. Oxford: Blackwell Publishers.

Moleong, Lexy J. (2007). Metodologi Penelitian Kualitatif. Bandung: Remaja Rosdakarya

Muhtar, Kamal. (2002). Asas-asas Hukum Islam tentang Perkawinan, Jakarta: Bulan Bintang

Nurgiyantoro, Burhan. (2009). Teori Pengkajian Fiksi. Yogyakarta: Gadjah Mada University Press.

Ratna, Nyoman Kutha. (2005). Teori, Metode dan Teknik Penelitian Sastra.

Rukminto, Isbandi. (2008). Intervensi Komunitas Pengembangan Masyarakat sebagai Upaya Pemberdayaan Masyarakat. Jakarta: Rajawali Pers.

Santoso, Widjajanti M. (2003). Sosiologi Feminisme, Konstruksi Perempuan dalam Industri Media. Yogyakarta: LKiS.

Saptari, dan Holzner, Brigitte. (1997). Perempuan Kerja dan Perubahan Sosial: Sebuah Pengantar Studi Perempuan. Grafiti. Jakarta.

Saryono. (2009). Pengantar Apresiasi Sastra. Malang: Universitas Negeri Malang.

Sugihastuti, Suharto. (2002). Kritik Sastra Feminis, Teori dan Aplikasinya. Yogyakarta: Pustaka Pelajar

Sargent, Lyrnan Tower. (2007). Ideologiideologi Politik Kontemporer. Jakarta: Erlangga.

Schiffrin, Deborah. (1994). Approach to Discourse. Massachusetts: Blackwell Publishers.

Simega. (2013). Ideologi Gender: Kesenjangan Sikap Tokoh Lewat Pernikahan Campur Antara Timur dan Barat.

Simpson, M.G. (1993). Plant Systematics. Elsevier Academic Press, USA

Sugihastuti \& Suharto. (2002). Gender dan Inferioritas Perempuan (Praktik Kritik Sastra Feminins). Yogyakarta: Pustaka Pelajar.

Sumarlam. (2010). Teori dan Prktik Analisis Wacana. Surakarta: Pustaka Cakra.

Suroto. (1993). Teori dan Bimbingan Apresiasi Sastra INDONESIA untuk SMTA (Jakarta: ErlanggGunawan Setiardja, Hak-Hak Asasi Manusia Berdasarkan Ideologi Pancasila. Yogyakarta: Kanisius 
